\title{
Analysis of Domestic Violence Related Homicides in Los Angeles County: Media Portrayals, Demographics, and Precipitating Circumstances
}

\author{
Nicolle Perras ${ }^{1}$ (I) $\cdot$ Isabelle Sternfeld ${ }^{2} \cdot$ Shangnon Fei $^{1} \cdot$ Briah Fischer $^{1} \cdot$ Gabriela Richards $^{1} \cdot$ Katie Chun $^{1}$
}

Accepted: 9 September 2020 / Published online: 21 September 2020

(C) Springer Science+Business Media, LLC, part of Springer Nature 2020

\begin{abstract}
Intimate partner violence (IPV) remains a pressing public health issue. Nationally, 1 in 5 women and 1 in 10 men have sustained severe physical violence from an intimate partner. Intimate partner homicides (IPH) are the most serious IPV outcome. This study examined documented IPH in Los Angeles County during 2017, analyzing if precipitating circumstances, victim demographics, victim/suspect relationship, and weapon type were related to how often a homicide was reported in online media stories. Cases were identified from the National Violent Death Reporting System (NVDRS), and standardized internet searches identified media articles associated with each case. Victim demographics from NVDRS and media articles were compared using Chi Square tests. Media report frequency, within different categorical predictor values, were examined using ANOVA models. 44 incidents were identified; averaging 5.2 articles per decedent. Univariate analyses showed significant difference in media reporting by poverty level (low versus high socioeconomic status) and presence of preceding argument. Multivariate analyses found significantly more media reports $(p=0.002)$ for incidents in which a preceding argument is reported, the victim was 3039 years old and from a low socioeconomic status zip code. From our results certain characteristics of IPH are associated with greater media reporting. Promotion of consistent and responsible IPH media reporting guidelines is an opportunity to reinforce public health messaging and dispel myths. In turn, this will encourage the development of future policies and funding streams across the spectrum of preventing and stopping IPV.
\end{abstract}

Keywords Homicide $\cdot$ Domestic violence $\cdot$ NVDRS $\cdot$ Media reporting $\cdot$ Firearms

\section{Introduction}

Intimate partner violence (IPV) continues to be a prevalent public health issue. Recent estimates report that 1 in 5 women and 1 in 10 men in the United States have sustained severe physical violence from an intimate partner over their lifetime (Smith et al. 2018). Numerous studies have documented the lasting impacts of IPV (Campbell 2002; Coker et al. 2002; Plichta 2004) with the most severe physical consequence of

Nicolle Perras

nperras@ph.lacounty.gov; nsperras@yahoo.com

1 Los Angeles County Department of Public Health, Office of Women's Health, 1000 S. Fremont Ave., Bldg. A-9 East, 5th Floor, Alhambra, CA 91803, USA

2 Los Angeles County Department of Public Health, Office of Violence Prevention, 1000 S. Fremont Ave., Bldg. A-9 East, 5th Floor, Alhambra, CA 91803, USA death. In the United States, over half of all females murdered $(55.3 \%)$ are killed by a current or former intimate partner (Petrosky et al. 2017). Rates of female homicide do show some variation by decedent race and ethnicity. Non-Hispanic black and American Indian/Alaska Native women experience the highest rates (4.4 and 4.3 per 100,000 population) compared to their Hispanic, white, and Asian and Pacific Islander counterparts $(1.8,1.5$ and 1.2 per 100,000 population) respectively (Petrosky et al. 2017).

Research on media coverage of IPV and IPH cases have repeatedly shown several overarching themes including reinforcement of gender stereotypes, perception of IPV as a "private issue," victim blaming, and limited media coverage of same-sex incidents. (Carlyle et al. 2014; Estes and Webber 2017; Lloyd and Ramon 2017; Savage et al. 2017; Scarduzio et al. 2017). These simplified narratives sensationalize victims and perpetrators, homicide circumstances and settings and continue to frame IPH as isolated events instead of as the culmination of complex problems and the escalation 
of ongoing violence (Carlyle et al. 2014; Estes and Webber 2017; Lloyd and Ramon 2017; Savage et al. 2017; Scarduzio et al. 2017). Omitting the social context of IPV and IPH in media reporting fuels the myth that these are personal, isolated events rather than showing IPV within its true cycle of violence. In addition, this type of reporting does not address power and control issues related to IPV as a social problem or discuss the impact on partners and families across geographies, socioeconomic status (SES), gender, and sexual identities (Easteal et al. 2018; Richards et al. 2011; Taylor and Sorenson 2002).

While domestic violence best practice reporting guidelines for media do exist, most media reports continue to rely on law enforcement sources rather than the broader perspective of IPV provided by public health experts (Sutherland et al. 2016). The few analyses addressing these issues include a study of 226 cases of IPH in North Carolina which found that newspaper coverage only framed $25 \%$ of incidents as a social problem and one ecological study of 340 IPH covered by Spanish television that found evidence of a small copycat effect in IPH rates during days in which these stories appeared compared to days without IPH-related news (Richards et al. 2011; Vives-Cases et al. 2009). However, research examining the consistency between data on IPH and the information relayed in media articles about these incidents is still relatively unexplored.

The current study utilizes National Violent Death Reporting System (NVDRS) data to understand the demographics and circumstances of victims of IPH in Los Angeles County. For each death identified in NVDRS, a series of searches were conducted to locate media articles for each IPH incident. Demographics and incident circumstances reported in the identified news reports were then compared to look at variable consistency across media articles and the NVDRS dataset. Finally, we examined how victim demographics and/or incident characteristics as reported in NVDRS were related to the frequency with which an IPH was reported in the media. The goal of comparing demographics of IPH victims along with media reports is twofold: first to identify and understand current media reporting practices of IPH and secondly to guide best practices to reduce inaccurate narratives and violence contagion both previously shown to be associated specifically with reporting of IPH.

\section{Methods}

\section{Description of NVDRS Surveillance System}

The National Violent Death Reporting System (NVDRS) was developed by the Centers for Disease Control and Prevention to collect comprehensive information on violent deaths, including victim demographics, incident characteristics (e.g. weapon used, event location), results of toxicology tests, and circumstances that were related to the fatal incident (i.e. gangrelated, mental health diagnosis, intimate partner violence). Additionally, NVDRS is an incident-based system, which means that multiple related deaths are linked together. NVDRS uses multiple sources to collect information about violent deaths: death certificates, coroner/medical examiner records, and law enforcement reports. This use of multiple sources means NVDRS provides more complete information about each incident than any single source alone. NVDRS is a state-based system, and California has been participating since 2017. In Los Angeles County, the Department of Public Health's Office of Violence Prevention (OVP) is responsible for collecting and abstracting NVDRS data on all violent deaths in the county. A detailed description of NVDRS and recent data has been published by the Centers for Disease Control and Prevention (Ertl et al. 2019).

In Los Angeles County (LAC), NVDRS collects data from death certificates including decedent's demographics, residence and event addresses, and cause and manner of death; this information is automatically imported into the system. Additional data are entered into NVDRS by trained abstractors at OVP who read LAC Medical Examiner/Coroner, LA Sheriff's Department, LA Police Department, and Long Beach Police Department case reports to gather information about the circumstances leading to each violent death. The abstractors review information provided from death certificates, updating any missing values with information gathered from other sources. Abstractors also review news stories for additional information about deaths by performing a google search for the victim's name; however, only facts that are cited in an article as coming directly from a law enforcement source are entered in NVDRS.

\section{Identifying Deaths from Intimate Partner Violence}

There are two sources that NVDRS uses to identify if a death is related to IPH: 1) the coroner/medical examiner and 2) law enforcement. NVDRS uses a broad definition of IPV, encompassing violence which results in the death of a current or former intimate partner. A separate variable describes the relationship between the victim and the suspect. For this study, IPH cases were defined as all cases where either the coroner/medical examiner or law enforcement considered the death to be related to IPV and where the relationship between the victim and the suspect was that of current or former spouse or girl/boyfriend. Victims whose death was related to IPV but who were not killed by an intimate partner (i.e. a child killed because of violence between his/her parents) were not included in this study. This exclusion was made to keep fidelity to the variable of IPH and control for skewed media reporting focused on bystanders and non-intended victims versus the targeted intimate partner. 


\section{Demographics and Incident Characteristics}

For each victim of IPH, we used information obtained from NVDRS to classify the victim's demographics and selected incident circumstances. These variables included the victim's gender, race/ethnicity (Hispanic, non-Hispanic black, white, Asian, Other/Unknown), age, country of birth (United States, Mexico, other), education level (less than high school, high school diploma/GED, more than high school), relationship between the victim and the suspect (current partner, former partner), weapon type (firearm, other), if the suspect died by suicide after committing IPH (yes, no), where the incident occurred (house/residence, other), if an argument preceded the death (yes, no), and postmortem toxicology tests of the victim (yes for any positive toxicology result, no positive toxicology results). We created a dichotomous variable to show whether or not a victim had positive postmortem toxicology test results; however, the number of toxicology tests performed on each victim varied, including 4 victims for whom no toxicology tests were conducted. Reporting of these variables was generally complete; however, one victim had unknown race/ethnicity, one had unknown educational level, and birthplace was unknown for three victims; analyses for those variables exclude victims with missing information.

In some cases, the multiple sources used for NVDRS provide conflicting information about a particular characteristic. In these instances, data abstractors are trained to confer with each other and their supervisor to reach a consensus about which data source is likely to be most accurate.

Finally, we used data from the 2017 American Community Survey (ACS) (US Census, 2013-2017 American Community Survey 5-year estimates, Table S1701-Poverty Status in the Past 12 Months) to categorize the victim's residential zip code based on how the level of poverty in the zip code compared to the overall LAC poverty level. Overall in LAC, $17 \%$ of the population lived below the poverty level; we classified zip codes with a greater percentage of the population living under the poverty level as "low SES", and zip codes with a smaller percentage of the population living under the poverty level as "high SES" geographic areas. Even though we only looked at poverty and not other factors related to SES, we use this language throughout the paper to avoid confusion since lower poverty actually equates to higher household income. The ACS data we used for this variable are provided for zip code tabulation areas; however, we treated this as an estimate of the zip code's poverty level.

All analyses were based on victim characteristics. While NVDRS does collect information on suspect demographics, it does not gather information on the suspect's suspected/ known drug use, residence location, or other characteristics that may have been related to the IPH incident.

\section{Media Reports}

For each IPH, we conducted media article searches using a variety of sources. Initially, we searched the Los Angeles Times Homicide Report (https://homicide.latimes.com). Next, searches were conducted via Lexis Nexis using the search term template: "first, last name (including maiden) of decedent, age of decedent". Lastly, Google searches were conducted with the same search term template used in Lexis Nexis described above. Review of search results were limited to the first three pages of results, were not focused on a specific time frame for publication and were conducted during Fall of 2019. Blogs and forum-based websites were excluded, as were articles from "City News Service", as those were predominantly gathered in the Lexis Nexis searches.

Results were reviewed and quantified for the following: total number of media articles per incident, and characteristics of the victim and the incident: gender (male, female, unmentioned), race/ethnicity (Asian, black, Hispanic, white, other, unmentioned), weapon type (firearm, sharp instrument, other, unmentioned). For each variable, the most commonly reported value among all news articles for each IPH case was assessed. If two different categories were equally represented in media reporting for a case, then the variable for that case was considered missing. For example, if an equal number of articles described a victim as black or white, race/ethnicity was coded as missing. Race/ ethnicity was also collapsed to an ethnicity variable (Hispanic vs. non-Hispanic) to allow for analyses exploring ethnicity when numbers were too small to examine race/ ethnicity in combination.

\section{Analysis - Comparison of Media Reporting with NVDRS}

First, we compared the information contained in each media report to the NVDRS database to look for consistency of reporting three variables: age, ethnicity, and weapon type. The frequency with which media reporting matched with NVDRS was computed. To understand if certain ethnicity was related to media reporting, a Chi Square test was used to compare whether the victim's ethnicity (Hispanic vs nonHispanic) was related to the frequency with which media reports mentioned race/ethnicity.

\section{Analysis - Frequency of Reporting in Media}

The total number of articles was calculated for each IPH case. We then calculated the average number of articles for deaths of people from different demographic groups and with different incident characteristics. For categorical predictor variables, we used one-way analysis of variance 
(ANOVAs) to compare the average number of articles identified for different groups. For the continuous predictor variable (age), we classified age into groups for ANOVA testing and ran correlations to examine the relationship between the predictor and the total number of articles reported for each case. For all ANOVAs, we evaluated the homogeneity of variance using Levene's test, and where needed, we used Welch's ANOVAs to account for heterogeneous variances. Finally, we combined factors with significant or near significant results and additional one-way ANOVAs were used to evaluate the significance of multiple variables simultaneously. We used SAS version 9.4 (SAS Institute, Cary, North Carolina) for all analyses.

\section{Results}

We identified 45 victims of IPH in LAC during 2017. One victim presented as an outlier with a larger media presence due to the victim's status in the community prior to death. Abstractors identified more than twice as many articles for this victim than for any other IPH case, and including this case more than doubled the average number of cases reported for male victims. Including this case substantially impacted our analyses, and since the media reporting for this victim seemed to be related more to the victim's status prior to death than to details related to the IPH, we chose to remove this victim from our analyses. All results presented here are for the 44 remaining IPH cases.

\section{Information in Media Reports}

Media reports frequently mentioned the weapon used and the victim's age, and the media reporting generally matched with NVDRS; $98 \%$ of weapons and $91 \%$ of age of victims were consistently reported in both sources. For race/ethnicity, $61 \%$ of articles did not mention race/ethnicity and only $25 \%$ of media reports mentioned a race/ethnicity that matched with the NVDRS data (Table 1). A Chi Square test showed that there was no significant association between Hispanic race/ ethnicity reported in NVDRS and whether race/ethnicity was reported in media $\left[\mathrm{X}^{2}(1, N=44)=1.3, p=.26\right]$.

Table 1 Total number of media articles that matched with description of NVDRS data, per decedent

\begin{tabular}{llll}
\hline Item & Positive matches & Not matched & Missing \\
\hline Weapon & 43 & 1 & 0 \\
Age & 40 & 4 & 0 \\
Race/Ethnicity & 11 & 6 & 27 \\
\hline
\end{tabular}

\section{Decedent Demographics}

For the 44 IPH victims, we identified an average of 5.2 articles per death, with a range of 1 to 21 . Most victims were female $(89 \%)$ and over half were Hispanic (59\%). The average age of victims was 37.6 years. Over half of the victims were born in the US (59\%), while almost one quarter were born in Mexico (23\%). Almost half of the victims had education beyond a high school degree (46\%) and half (50\%) lived in a low SES zip code.

Over half of deaths involved a firearm (55\%) and nearly three quarters $(73 \%)$ occurred in a house or apartment. In one third of the cases an argument was reported to have preceded the death. Just under one third (32\%) of victims had a positive toxicology test. Most victims were killed by a current (77\%) rather than a former (23\%) partner. In $30 \%$ of the cases, the suspect died by suicide after killing the victim (Table 2).

\section{Presence and Comparisons of Media Articles per Victims}

Table 2 summarizes these findings and includes the average number of articles identified for victims in each of these demographic groups and incident categories. Victims identified as black, aged 30-39 years, living in high SES zip codes, or killed by a former intimate partner all had an average of over 7 articles identified for each death. Victims born in Mexico, aged 40+, living in low SES zip codes, or who were involved in an argument prior to death all had an average of 3.5 articles or fewer identified for each death.

Table 2 also shows the results from one-way ANOVA tests comparing the average number of articles found for each demographic and incident characteristic group. Significantly fewer articles $(p<0.03)$ were identified for cases in which the victim had been involved in an argument (3.1), than for those victims who had not been involved in an argument (6.3). This was also true for victims living in low SES zip codes (3.5; $p<0.008)$ compared to low poverty zip codes (7.2).

To further investigate the significant results of argument and SES, ANOVAs were conducted by combining the significant argument and SES factors with age group factor (Table 3). Fitting an ANOVA model with all three of these factors resulted in a significant model $(p=0.002)$, with an $\mathrm{R}^{2}$ value of 0.58 . Victims aged 30-39 living in high SES zip codes with no reported argument prior to death were most mentioned in media reports, with an average of 14.3 articles per death. By comparison, victims aged $40+$ years old living in low SES zip codes who had been involved in an argument prior to death had an average of only 1.3 reported articles per death. These discrepancies in media reporting of IPH reinforce false narratives and minimize risk of IPV and IPH to all communities. 
Table 2 Average number of media articles by decedent/incident characteristic and univariate ANOVA results

\begin{tabular}{|c|c|c|c|c|c|}
\hline Characteristic & Category & \# of victims & $\%$ & Avg \# of articles & ANOVA for difference \\
\hline \multirow[b]{2}{*}{ Gender } & Total & 44 & 100 & 5.2 & \multirow[b]{2}{*}{$p=0.61$} \\
\hline & $\begin{array}{l}\text { Female } \\
\text { Male }\end{array}$ & $\begin{array}{l}39 \\
5\end{array}$ & $\begin{array}{l}88.6 \% \\
11.4 \%\end{array}$ & $\begin{array}{l}5.3 \\
4.2\end{array}$ & \\
\hline \multirow[t]{4}{*}{ Race/Ethnicity } & $\begin{array}{l}\text { Hispanic } \\
\text { Black }\end{array}$ & $\begin{array}{l}26 \\
4\end{array}$ & $\begin{array}{l}59.1 \% \\
9.1 \%\end{array}$ & $\begin{array}{l}4.9 \\
7.5\end{array}$ & \multirow[t]{4}{*}{$p=0.71$} \\
\hline & Asian & 5 & $11.4 \%$ & 6.4 & \\
\hline & White & 8 & $18.2 \%$ & 4.9 & \\
\hline & Unknown $^{\mathrm{a}}$ & 1 & $2.3 \%$ & 1 & \\
\hline \multirow[t]{3}{*}{ Country of birth } & $\begin{array}{l}\text { US } \\
\text { Mexico }\end{array}$ & $\begin{array}{l}26 \\
10\end{array}$ & $\begin{array}{l}59.1 \% \\
22.7 \%\end{array}$ & $\begin{array}{l}6 \\
3.5\end{array}$ & \multirow[t]{3}{*}{$p=0.36$} \\
\hline & Other & 7 & $15.9 \%$ & 5.3 & \\
\hline & Unknown $^{\mathrm{a}}$ & 1 & $2.3 \%$ & 1 & \\
\hline \multirow[t]{3}{*}{ Education level } & $\begin{array}{l}<\text { High School } \\
\text { High School/GED }\end{array}$ & $\begin{array}{l}6 \\
17\end{array}$ & $\begin{array}{l}13.6 \% \\
38.6 \%\end{array}$ & $\begin{array}{l}5 \\
5.1\end{array}$ & \multirow[t]{3}{*}{$p=0.95$} \\
\hline & More than HS & 20 & $45.5 \%$ & 5.6 & \\
\hline & Unknown $^{\mathrm{a}}$ & 1 & $2.3 \%$ & 1 & \\
\hline \multirow[t]{2}{*}{ Age group } & $\begin{array}{l}<30 \text { Years } \\
30-39 \text { Years }\end{array}$ & $\begin{array}{l}15 \\
15\end{array}$ & $\begin{array}{l}34.1 \% \\
34.1 \%\end{array}$ & $\begin{array}{l}4.9 \\
7.1\end{array}$ & \multirow[t]{2}{*}{$p=0.10$} \\
\hline & $40+$ Years & 14 & $31.8 \%$ & 3.5 & \\
\hline \multirow[t]{2}{*}{ Weapon used } & $\begin{array}{l}\text { Firearm } \\
\text { Sharp }\end{array}$ & $\begin{array}{l}24 \\
15\end{array}$ & $\begin{array}{l}54.5 \% \\
34.1 \%\end{array}$ & $\begin{array}{l}5.8 \\
4.7\end{array}$ & \multirow[t]{2}{*}{$p=0.62$} \\
\hline & Other & 5 & $11.4 \%$ & 3.8 & \\
\hline Type of incident & $\begin{array}{l}\text { Homi-Sui } \\
\text { Homi Only }\end{array}$ & $\begin{array}{l}13 \\
31\end{array}$ & $\begin{array}{l}29.5 \% \\
70.5 \%\end{array}$ & $\begin{array}{l}4.6 \\
5.5\end{array}$ & $p=0.59$ \\
\hline Victim suspect relationship & $\begin{array}{l}\text { Current Partner } \\
\text { Former Partner }\end{array}$ & $\begin{array}{l}34 \\
10\end{array}$ & $\begin{array}{l}77.3 \% \\
22.7 \%\end{array}$ & $\begin{array}{l}4.6 \\
7.1\end{array}$ & $p=0.35$ \\
\hline Did an argument precede the death? & $\begin{array}{l}\text { Argument } \\
\text { No Argument }\end{array}$ & $\begin{array}{l}15 \\
29\end{array}$ & $\begin{array}{l}34.1 \% \\
65.9 \%\end{array}$ & $\begin{array}{l}3.1 \\
6.3\end{array}$ & $p=0.03$ \\
\hline Where did the incident occur? & $\begin{array}{l}\text { House } \\
\text { Other Location }\end{array}$ & $\begin{array}{l}32 \\
12\end{array}$ & $\begin{array}{l}72.7 \% \\
27.3 \%\end{array}$ & $\begin{array}{l}5.4 \\
4.8\end{array}$ & $p=0.70$ \\
\hline Toxicology results & $\begin{array}{l}\text { Positive Tox } \\
\text { No Positive Tox }\end{array}$ & $\begin{array}{l}14 \\
30\end{array}$ & $\begin{array}{l}31.8 \% \\
68.2 \%\end{array}$ & $\begin{array}{l}4.4 \\
5.6\end{array}$ & $p=0.46$ \\
\hline \multirow[t]{2}{*}{$\begin{array}{l}\text { Socioeconomic status (\% Poverty } \\
\text { in Residential Zip Code) }\end{array}$} & $\begin{array}{l}\text { Low SES } \\
\text { High SES }\end{array}$ & $\begin{array}{l}22 \\
21\end{array}$ & $\begin{array}{l}50.0 \% \\
47.7 \%\end{array}$ & $\begin{array}{l}3.5 \\
7.2\end{array}$ & \multirow[t]{2}{*}{$p=0.008$} \\
\hline & Unknown $^{\mathrm{a}}$ & 1 & $2.3 \%$ & 1 & \\
\hline
\end{tabular}

${ }^{a}$ Victims with unknown values not included in analysis

\section{Discussion}

The current study provides information on the demographics of victims of IPH in LAC. Additionally, we examined how the media reported details of each IPH case compared to NVDRS data. Our analyses revealed significant disparities in media coverage of IPH cases by age, race and SES. The average number of media articles were higher for Black and Asian IPH victims (7.5 and 6.4), compared to white and Hispanic IPH victims (4.9 articles). Significantly more media articles were found for IPH victims between 30 and 39 years old, living in high SES zip codes with no reported argument prior to death. This also highlights the intersectionality of race, age and SES in which murders are more likely to garner media coverage when IPH victims are younger and from more affluent communities. These patterns are significant in promoting inconsistent and pervasive societal myths surrounding IPH including that IPH is less common in wealthier neighborhoods and more "news worthy" when the victim is relatively young. The narrow coverage of IPH incidents to those deemed "news worthy" or somehow "out of the norm" versus universal coverage of IPH, reinforces simplified narratives surrounding IPH and propels misperceptions that not all populations are at risk for IPV and IPH.

In our univariate analyses, we found that the frequency of media reporting did not vary by demographic factors. Media 
Table 3 Multivariate ANOVAs examining age, poverty and argument status identified in One Way ANOVAs

\begin{tabular}{|c|c|c|c|c|c|}
\hline Combined characteristics & Category & \# of victims & $\%$ & $\begin{array}{l}\text { Avg \# of } \\
\text { articles }\end{array}$ & $\begin{array}{l}\text { ANOVA for } \\
\text { difference }\end{array}$ \\
\hline \multirow[t]{6}{*}{ Argument \& Age group } & No Argument, $<30$ Years & 9 & $20.5 \%$ & 5.2 & \multirow[t]{6}{*}{$p=0.07$} \\
\hline & No Argument, 30-39 Years & 11 & $25.0 \%$ & 8.5 & \\
\hline & No Argument, 40+ Years & 9 & $20.5 \%$ & 4.6 & \\
\hline & Argument, $<30$ Years & 6 & $13.6 \%$ & 4.3 & \\
\hline & Argument, 30-39 Years & 4 & $9.1 \%$ & 3.3 & \\
\hline & Argument, $40+$ Years & 5 & $11.4 \%$ & 1.6 & \\
\hline \multirow[t]{4}{*}{ Argument \& Poverty } & No Argument, Low Poverty & 17 & $38.6 \%$ & 8 & \multirow[t]{4}{*}{$p=0.01$} \\
\hline & No Argument, High Poverty & 11 & $25.0 \%$ & 4.1 & \\
\hline & Argument, Low Poverty & 4 & $9.1 \%$ & 3.8 & \\
\hline & Argument, High Poverty & 11 & $25.0 \%$ & 2.9 & \\
\hline \multirow[t]{6}{*}{ SES \& Age group } & High SES, $<30$ Years & 8 & $18.2 \%$ & 6.6 & \multirow[t]{6}{*}{$p=0.0006$} \\
\hline & High SES, 30-39 Years & 6 & $13.6 \%$ & 10 & \\
\hline & High SES, 40+ Years & 7 & $15.9 \%$ & 5.4 & \\
\hline & Low SES, $<30$ Years & 7 & $15.9 \%$ & 2.9 & \\
\hline & Low SES, 30-39 Years & 8 & $18.2 \%$ & 5.8 & \\
\hline & Low SES, 40+ Years & 7 & $15.9 \%$ & 1.6 & \\
\hline \multirow{12}{*}{$\begin{array}{l}\text { Argument, relationship } \\
\text { type, and SES }\end{array}$} & No Argument, High SES, <30 Years & 7 & $15.9 \%$ & 6.3 & \multirow[t]{12}{*}{$p=0.002$} \\
\hline & No Argument, High SES, 30-39 Years & 4 & $9.1 \%$ & 14.3 & \\
\hline & No Argument, High SES, 40+ Years & 6 & $13.6 \%$ & 5.8 & \\
\hline & No Argument, Low SES, <30 Years & 2 & $4.5 \%$ & 1.5 & \\
\hline & No Argument, Low SES, 30-39 Years & 6 & $13.6 \%$ & 6 & \\
\hline & No Argument, Low SES, 40+ Years & 3 & $6.8 \%$ & 2 & \\
\hline & Argument, High SES, <30 Years & 1 & $2.3 \%$ & 9 & \\
\hline & Argument, High SES, 30-39 Years & 2 & $4.5 \%$ & 1.5 & \\
\hline & Argument, High SES, 40+ Years & 1 & $2.3 \%$ & 3 & \\
\hline & Argument, Low SES, <30 Years & 5 & $11.4 \%$ & 3.4 & \\
\hline & Argument, Low SES, 30-39 Years & 2 & $4.5 \%$ & 5 & \\
\hline & Argument, Low SES, 40+ Years & 4 & $9.1 \%$ & 1.3 & \\
\hline
\end{tabular}

reporting was significantly more frequent for victims living in high SES zip codes and for whom there was no record of an argument prior to death. Our finding of no demographic differences in media reports differs from existing research on the media reporting of homicides in general. A study of all homicides in LAC showed that media articles disproportionately featured victims who were female, white or Asian, and younger (under 40) or older (60 and over) (Sorenson et al. 1998). In our multivariate model, age was a significant predictor when looked at in combination with SES level and the presence of an argument. However, even in our univariate models the greatest number of articles were found for victims in our middle age range: 30-39 year-olds, with results approaching significance $(p=0.10)$. We also found that the deaths of victims who had not been reported to be in an argument prior to death received more media coverage. This skewed reporting of IPH misses the opportunity of universal media reporting to document the cycle of IPV and its escalation to turn deadly in some instances. If investigations into these deaths were less likely to immediately identify a suspect, that may have increased media attention. Additionally, these incidents may run counter to mainstream perceptions of IPH resulting from a "heated argument" that "turns deadly" or "escalates" versus an intentional act of murder. More research into the content of the published articles may help clarify this finding.

Finally, our analysis determined that victims who lived in lower SES zip codes received less media coverage. This finding is supported by existing research that has shown that reporting is more common for victims from wealthier neighborhoods (Sorenson and Schut 2016; Sorenson et al. 1998). We speculate this difference might stem from enduring misperceptions that IPV, and IPH in particular, are less likely to occur in wealthier communities compared to more impoverished neighborhoods. Regardless, this differential reporting can be harmful in perpetuating misconceptions and myths of the scope of IPH, and its impact on diverse populations. Coupled with the failure to consistently present IPV and IPH as widespread social problems, discussion around 
prevention and intervention are missing from the media discourse. This continued omission from media portrayals of IPH hinders prevention efforts and policy development designed to comprehensively address the nature of IPV's cycle of violence and abuse for all communities.

Although we identified cases of IPH using data from NVDRS, we may not have identified all homicide victims who were killed by an intimate partner. In particular, local law enforcement agencies that provide records to NVDRS only investigate around $75 \%$ of countywide homicides. For the cases we did identify, the completeness of the information provided by data sources varied from case to case, and in some instances data sources provided conflicting information, which may have led to missing or inaccurate information being reported. Additionally, the criteria used to identify media articles for each case used the victim's name and age, thus inconsistent spelling or other inaccurate reporting would limit the number of articles found for a given victim. Cities with municipal police departments that do not currently provide records include areas with both some the highest (Bell Gardens, 29.9\% in poverty) and lowest (Manhattan Beach, $3.3 \%$ in poverty) poverty rates, indicating that lack of law enforcement records from these diverse agencies would not likely impact our findings related to poverty/SES. We do not see that our significant findings focused on SES, age, and arguments would likely be biased in particular direction due to the limitations described here.

\section{Conclusion}

The current study emphasizes the continued inequalities and disparities in media reporting on IPH, including highlighting the intersectionality of a victim's race, age and SES. Further examination is needed regarding media reporting practices of IPH, including differences based on a victim's history of IPV. Research has shown that media coverage of IPH is less likely to be emotionally-driven or to provide context for the murder compared to media articles about other types of homicides (Taylor and Sorenson 2002). The pervasiveness of this type of narrative provides a significant barrier to dispelling myths around IPV. It also fails to encourage social change or to highlight the need for IPV prevention and intervention resources in all communities. While our work shows that there are differences in frequency of reporting based upon IPH characteristics, additional research is needed to see if the tone and content of reporting varies based on known precipitating factors (e.g. argument) and/or victim's characteristics (e.g. economic status).

Additionally, new research can also explore how current media reporting practices of IPH and IPV influence social perceptions of these forms of violence. Ultimately, future work should focus on the education, assistance and evaluation of media implementation of existing IPV reporting guidelines (DART Center for Journalism and Trauma (2012); Rhode Island Coalition Against Domestic Violence 2015). Encouraging the incorporation of advocate and public health voices into media articles can help to address the complexities of IPV and to provide resources and social context. IPH media reporting guidelines could reduce existing biases in reporting and address the spread of misinformation and misperceptions about IPH and IPV. similar to suicide reporting guidelines designed to thwart suicide contagion.

Efforts are needed to develop more robust datasets that allow for a deeper look into the circumstances and demographic information surrounding victims and perpetrators of IPV and IPH. These efforts should include the development of IPV-focused data surveillance systems to measure the prevalence of all forms of IPV including physical, emotional and psychological. Identification and reporting on the spectrum of violence, abuse and control involved in IPV is essential in illustrating its progression and points for intervention. Expansion of NVDRS to increase data sharing among law enforcement jurisdictions would greatly assist in correctly identifying IPH and potentially provide context of IPV histories. Improved access to and reporting of circumstances such as drug/alcohol use, mental health issues, custody issues, legal problems, unemployment, financial stressors and physical health problems could lay broader context for IPH. Deeper understanding of common relationship stressors contributing to violence could greatly inform and interventions and resources to assist. The interactions between these factors also provide vital information for prevention efforts.

Dispelling common myths around IPV and IPH, increased and more robust data related to the complexities and spectrum of relationship violence and abuse and broader context of IPV as a social problem are needed now more than ever. The current COVID-19 global pandemic has increased the risk of IPV and IPH for many populations with mandatory stay at home orders increasing isolation and reducing social supports. Additionally, economic hardships and reduced access to services and resources have also been concerns. Thankfully many agencies and service providers have quickly adapted and are providing services virtually. Concurrently we have also seen media reports of increased IPV.

The narrative and talking points in our media outlets, criminal justice systems and legislative bodies need to evolve. IPV needs to be truly seen for the preventable, social problem it is. The devastating impacts IPV continues to have on the health, wellbeing and safety of individuals, families and communities globally can be stopped. Our recommendations highlight the persistent need for increased resourcing of overall public health efforts (e.g. policy, data, and public education) to address and prevent IPV among all populations. 


\section{References}

Campbell, J. C. (2002). Health consequences of intimate partner violence. Lancet, 359(9314), 1331-1336. https://doi.org/10.1016/S01406736(02)08336-8.

Carlyle, K. E., Scarduzio, J. A., \& Slater, M. D. (2014). Media portrayals of female perpetrators of intimate partner violence. Journal of Interpersonal Violence, 29(13), 2394-2417. https://doi.org/10. $1177 / 0886260513520231$.

Coker, A. L., Davis, K. E., Arias, I., Desai, S., Sanderson, M., Brandt, H. M., et al. (2002). Physical and mental health effects of intimate partner violence for men and women. American Journal of Preventive Medicine, 23(4), 260-268. https://doi.org/10.1016/ S0749-3797(02)00514-7.

DART Center for Journalism \& Trauma. (2012). The Legwork: Where to look, what questions to ask. Retrieved from https://artcenter.org/ content/legwork-where-to-look-what-questions-to-ask

Easteal, P., Holland, K., Breen, M. D., Vaughan, C., \& Sutherland, G. (2018). Australian media messages: critical discourse analysis of two intimate homicides involving domestic violence. Violence Against Women, 25(4), 441-462. https://doi.org/10.1177/ 1077801218780364.

Ertl, A., Sheats, K. J., Petrosky, E., Betz, C. J., Yuan, K., \& Fowler, K. A. (2019). Surveillance for violent deaths - national violent death reporting system, 32 States, 2016. Morbidity and Mortality Weekly Report. Surveillance Summaries (Washington, D.C. : 2002), 68(9), 1-36. https://doi.org/10.15585/mmwr.ss.6809a1.

Estes, M. L., \& Webber, G. R. (2017). "More closeted than gayness itself": the depiction of same-sex couple violence in newspaper media. Journal of Interpersonal Violence, 088626051773627. https:// doi.org/10.1177/0886260517736271.

Lloyd, M., \& Ramon, S. (2017). Smoke and mirrors: U.K. newspaper representations of intimate partner domestic violence. Violence Against Women, 23(1), 114-139. https://doi.org/10.1177/ 1077801216634468.

Petrosky, E., Blair, J. M., Betz, C. J., Fowler, K. A., Jack, S. P. D., \& Lyons, B. H. (2017). Racial and ethnic differences in homicides of adult women and the role of intimate partner violence - United States, 2003-2014. In Morbidity and Mortality Weekly Report (Vol. 66). https://doi.org/10.15585/mmwr.mm6628a1.

Plichta, S. B. (2004). Intimate partner violence and physical health consequences: policy and practice implications. Journal of Interpersonal Violence, 19(11), 1296-1323. https://doi.org/10. $1177 / 0886260504269685$.
Rhode Island Coalition Against Domestic Violence. (2015). Online guide for journalists. Retrieved from http://www.dvonlineguide.org/en/

Richards, T. N., Gillespie, L., \& Smith, M. D. (2011). Exploring news coverage of femicide: does reporting the news add insult to injury? Feminist Criminology, 6(3), 178-202. https://doi.org/10.1177/ 1557085111409919

Savage, M. W., Scarduzio, J. A., Lockwood Harris, K., Carlyle, K. E., \& Sheff, S. E. (2017). News stories of intimate partner violence: an experimental examination of participant sex, perpetrator sex, and violence severity on seriousness, sympathy, and punishment preferences. Health Communication, 32(6), 768-776. https://doi.org/10. 1080/10410236.2016.1217453.

Scarduzio, J. A., Carlyle, K. E., Harris, K. L., \& Savage, M. W. (2017). "Maybe she was provoked": exploring gender stereotypes about male and female perpetrators of intimate partner violence. Violence Against Women, 23(1), 89-113. https://doi.org/10.1177/ 1077801216636240

Smith, S. G., Zhang, X., Basile, K. C., Merrick, M. T., Wang, J., Kresnow, M., \& Chen, J. (2018). The National Intimate Partner and Sexual Violence Survey (NISVS): 2015 data brief. Atlanta: National Center for Injury Prevention and Control, Centers for Disease Control and Prevention.

Sorenson, S. B., \& Schut, R. A. (2016). Nonfatal gun use in intimate partner violence: a systematic review of the literature. Trauma, Violence, and Abuse, 19(4), 431-442. https://doi.org/10.1177/ 1524838016668589.

Sorenson, S. B., Peterson Manz, J. G., \& Berk, R. A. (1998). News media coverage and the epidemiology of homicide. American Journal of Public Health, 88(10), 1510-1514. https://doi.org/10.2105/AJPH. 88.10.1510.

Sutherland, G., McCormack, A., Easteal, P., Holland, K., \& Pirkis, J. (2016). Media guidelines for the responsible reporting of violence against women: a review of evidence and issues. Australian Journalism Review, 38(1), 5-17.

Taylor, C. A., \& Sorenson, S. B. (2002). The nature of newspaper coverage of homicide. Injury Prevention, 8(2), 121-127. https://doi.org/ 10.1136/ip.8.2.121.

Vives-Cases, C., Torrubiano-Domínguez, J., \& Álvarez-Dardet, C. (2009). The effect of television news items on intimate partner violence murders. European Journal of Public Health, 19(6), 592-596. https://doi.org/10.1093/eurpub/ckp086.

Publisher's Note Springer Nature remains neutral with regard to jurisdictional claims in published maps and institutional affiliations. 